\title{
ANTIFEEDANT EFFECTS OF VITEX NEGUNDO L. LEAF EXTRACTS ON THE STORED PRODUCT PEST, TRIBOLIUM CASTANEUM H. (COLEOPTERA: TENEBRIONIDAE)
}

\author{
P. HARIDASAN, M. GOKULDAS, A. P. AJAYKUMAR \\ Insect Physiology and Biochemistry Laboratory, Department of Zoology, University of Calicut, Kerala 673635, India \\ Email: dr.p.haridasan@gmail.com
}

Received: 09 Oct 2016 Revised and Accepted: 09 Jan 2017

\begin{abstract}
Objective: This study aims to evaluate the nutritional and feeding deterrence indices of Tribolium castaneum adults caused by petroleum ether and methanol extracts of Vitex negundo.

Methods: A modified method of flour disc bioassay was carried out to study the antifeedant activities of both the extracts on the stored product pest, T. castaneum. In this bioassay, the insects were allowed to feed on wheat flour treated with various concentrations $(1.25 \%$, $2.5 \%$ and $5 \%)$ of petroleum ether and methanol extracts of $V$. negundo (VPE and VME) for $24 \mathrm{~h}$ in 'no choice' chambers. The effects of different concentrations of the extracts on relative growth rate and relative consumption rate of T. castaneum and the difference between the activities of two extracts were statistically analysed and compared by analysis of covariance (ANCOVA). Similarly, the comparison of the activities of VPE and VME, and their dose effects on the efficiency of conversion of ingested food and feeding deterrence indices of the insects were analysed by analysis of variance (ANOVA).
\end{abstract}

Results: VPE and VME significantly affected growth, consumption and utilisation of food, and caused antifeedancy in T. castaneum. It was also found that both the extracts resulted in a slight reduction in growth rate of the insect, compared with that of the control. The reductions in relative growth rate (RGR) $(P=0.37)$ and relative food consumption rate (RCR) $(P<0.05)$ were more prominent for $2.5 \%$ and $5 \%$ of both the extracts. In nutritional studies, it was found that increase in the concentration $(P<0.05)$ resulted in an increase in the efficiency of conversion of ingested food (ECI) significantly with both the extracts. The RGR, RCR and ECI of the insects were found to be similar with both the extracts. The extracts showed dosedependent feeding deterrence index (FDI) for this insect $(P<0.001)$. The activity was found to be similar with both the extracts $(P=0.07)$.

Conclusion: The present study reveals that both VPE and VME show significant antifeedancy in T. castaneum and thus they can effectively be used for the protection of grains from insects.

Keywords: Vitex negundo, Tribolium castaneum, Nutritional index, Antifeedancy

(c) 2016 The Authors. Published by Innovare Academic Sciences Pvt Ltd. This is an open access article under the CC BY license (http://creativecommons.org/licenses/by/4. 0/) DOI: http://dx.doi.org/10.22159/ijpps.2017v9i3.15600

\section{INTRODUCTION}

Search for safer and more congenial alternatives for insect pest control using chemical insecticides has resulted in more attention getting focused on botanicals. Most of the plants contain different types of secondary metabolites that have various effects on many insect species. The active components from plants act on insect pests as toxins, repellents, antifeedants, ovicidals etc. Antifeedants prevent insects from feeding on vegetation, grain or other products leading them to starvation and subsequent death. Antifeedant activity is one of the principal bioactivities brought about by plant constituents on insects, which lend impetus to the incorporation of feeding deterrence strategy in integrated pest management (IPM) programmes, which ultimately lead insects to die of starvation. Since most of these antifeedant principles, derived from plants are non-toxic in nature, their environmental compatibility is an important advantage. Antifeedants of plant origin have the additional advantage of quick biodegradability and are friendly to non-target organisms. Hence, insect antifeedants have become the subject of considerable interest.

Many plant materials have been effectively used against stored product insects. Some studies have been carried out to investigate the antifeedant effect of pithraj, Aphanamixis polystachya on $T$. castaneum [1] and certain secondary plant compounds isolated from the sub-fractions of $A$. polystachya seed extract and the subfraction A-142 contained strong feeding deterrents that acted against $T$. castaneum [2]. Similarly, antifeedant properties of the rhizome extract of Acorus calamus have been investigated against $T$. castaneum [3]. Four sesquiterpene alkaloids isolated from Celastrus angulatus were also showing antifeedant activities on T. castaneum [4]. Similarly, antifeedancy of alkaloid-containing fraction isolated from the leaves of Nicotiana tabacum against the larvae of $T$. castaneum has been reported [5].
Vitex negundo is an aromatic shrub, found throughout the greater part of India. Almost all parts of this plant are valuable in medicine. Various preparations of this plant were reported to have antiinflammatory [6], antiulcer [7], larvicidal [8], antiasthmatic [9] and other biological properties. Even though many biological effects of $V$. negundo have been identified, its antifeedant effect has not been studied on T. castaneum until the present study.

In the light of abovementioned facts, the present investigation was carried out to investigate the nutritional and feeding deterrence indices ('no choice' feeding bioassay) for the stored grain pest, $T$. castaneum adults to $V$. negundo leaf extracts prepared in petroleum ether and methanol.

\section{MATERIALS AND METHODS}

\section{Materials}

The experimental plant, Vitex negundo Linnaeus (88485 CALI; Family: Verbenaceae) was used for the purpose of preparing extracts of leaves in petroleum ether (Glaxo BP $60-80^{\circ} \mathrm{C}$ ) and methanol (Merck) and for evaluating nutritional and feeding deterrent indices for the stored product pest, Tribolium castaneum Herbst (Coleoptera: Tenebrionidae) in the laboratory. The equipment/apparatus used in the study were electronic balance (Anamed, Sartorius), automatic shaker (Toshniwal), hot air oven (Kemi), vacuum pump and Büchner funnel.

\section{Methods}

\section{Insect culture}

Adults of the rust-red flour beetle, Tribolium castaneum were collected from local granaries and reared in the insectary in 
plastic jars $(13.5 \times 10 \mathrm{~cm})$ containing wheat flour. The culture was maintained at $26 \pm 2^{\circ} \mathrm{C}$ and $70-80 \% \mathrm{R} \mathrm{H}$. After $2 \mathrm{w}$, larvae, pupae and adults were separated by sifting the wheat flour with a fine meshed sieve and were transferred into clean jars containing fresh food. Freshly emerged adults were used for the bioassay.

\section{Preparation of plant extracts}

Leaves of $V$. negundo (Vellanochi-Malayalam) were collected from the Calicut University campus, Kerala, India $\left(11.1339^{\circ} \mathrm{N}, 75.8940^{\circ}\right.$ E). Fresh leaves were thoroughly washed in distilled water and shade dried at room temperature for a week and they were further dried for one day in a hot air oven maintained at $35-38^{\circ} \mathrm{C}$. The dried leaves were then powdered using a domestic grinder and sifted through a fine meshed sieve. The leaf powder was stored in airtight glass bottles at about $4^{\circ} \mathrm{C}$. The leaf powder was used for the preparation of $V$. negundo petroleum ether extract (VPE) and $V$. negundo methanol extract (VME).

Fifty grams of the powdered plant material was mixed with 200 $\mathrm{ml}$ of petroleum ether taken in a conical flask and the mixture was agitated on an automatic shaker for $24 \mathrm{~h}$ at room temperature keeping the flask tightly covered. The extract was then filtered through Whatman No. 1 filter paper by negative pressure using a Büchner funnel and a suction pump.

The residue was re-extracted in another $150 \mathrm{ml}$ of petroleum ether and filtered after $24 \mathrm{~h}$. The filtrates were combined and allowed to dry in a hot air oven maintained at $40^{\circ} \mathrm{C}$. The weight of the dried residue was determined. After ascertaining the final weight of the residue, $10 \%$ stock solution was prepared in petroleum ether. Other required dilutions were made using petroleum ether.

Similarly, VME was prepared using methanol as the extracting solvent instead of petroleum ether.

\section{Nutritional and feeding deterrence indices bioassay}

Nutritional and feeding deterrence indices for T. castaneum adults to the VPE and VME were studied by the method of 'no choice' test using extract-incorporated diet in the chamber. It is a modified method of flour disc bioassay [10]. Testing of this nutritional effect was conducted in the 'no choice' chambers. This consisted of separate plastic vials with perforated lids $(3.2 \mathrm{~cm}$ diameter x $4.5 \mathrm{~cm}$ height) containing diets incorporated with three concentrations of VPE (treated) and petroleum ether alone (control). The vials were labeled properly.

The extract-incorporated diet was prepared by mixing $150 \mu \mathrm{l}$ each of 1.25, 2.5 and 5\% concentrations of VPE added drop-wise into 150 $\mathrm{mg}$ of wheat flour taken in separate watch-glasses. Similarly, the same volume of petroleum ether alone was added into same quantity of wheat flour in a fourth watch glass (control). The contents of all the watch glasses were thoroughly mixed using separate glass rods and the solvent was allowed to evaporate completely at room temperature for about $3 \mathrm{~h}$. The 4 'no choice' chambers were weighed separately. Then $100 \mathrm{mg}$ each of the diet treated with different concentrations of VPE $(1.25,2.5$ and $5 \%)$ were added into the four vials ( 3 treated and 1 control).

Forty healthy adults, pre-starved for $24 \mathrm{~h}$ before the test, were weighed as 4 groups of 10 and released into the 4 pre-weighed vial ('no choice' chambers) containing the diet. They were kept in the insectary at room temperature for one day for consumption of the diet. After $24 \mathrm{~h}$, all insects were removed from the 'no choice chambers' and the live insects were weighed separately as 4 groups. Mortality of insects, if any, was recorded.

Also, each vial with lid plus flour diet was weighed to determine the decrease in weight of flour diet in control and the treated. Six replicates were used for each treatment and control. The experiment was repeated with the other extract, VME, in the same pattern as with VPE. The diet used for control was treated with methanol alone.

Nutritional indices were calculated as described by Manuwoto and Scriber 1982 [11]; Farrar et al., 1989 [12] with some modifications.

$$
R G R=\frac{(A-B)}{B} \times d a y
$$

$\mathrm{RGR}=$ Relative Growth Rate, where $\mathrm{A}=$ weight of live insects on one day $(\mathrm{mg}) /$ number of live insects on one day. $\mathrm{B}=$ initial weight of insects (mg)/initial number of insects.

$$
R C R=\frac{D}{B} \times d a y
$$

RCR = Relative Consumption Rate, where $\mathrm{D}=$ biomass ingested $(\mathrm{mg}) /$ number of live insects on one day.

$$
\operatorname{ECI}(\%)=\left(\frac{R G R}{R C R}\right) \times 100
$$

ECI \% = Percentage of Efficiency of Conversion of Ingested food.

Antifeedant activity (feeding deterrence activity) was calculated as Feeding Deterrence Index (Isman et al., 1990) [13].

$$
F D I(\%)=\left[\frac{(C-T)}{C}\right] \times 100
$$

FDI $\%=$ Percentage of Feeding Deterrence Index, where $\mathrm{C}=$ Consumption of control diet

\section{$\mathrm{T}=$ Consumption of treated diet.}

\section{Statistical analysis of the data}

The results are expressed as means+SEMs for 10 insects per group. The effects of different concentrations of the both the extracts on relative growth rate and relative consumption rate for $T$. castaneum were subjected to ANCOVA and efficiency of conversion of ingested food and feeding deterrence indices for the insects were analysed and compared by ANOVA.

\section{RESULTS}

Nutritional indices for $V$. negundo petroleum ether extract (VPE)

The relative growth rate (RGR) of insects for $24 \mathrm{~h}$ were showing a slight reduction in treated samples compared with the control and the RGR decreased with increase in the concentration of the extract. Thus, $1.25,2.5$ and $5 \%$ concentrations afforded the RGR of 0.040 , 0.033 and $0.028 \mathrm{mg} / \mathrm{mg} / \mathrm{d}$ respectively whereas in the control the value was $0.052 \mathrm{mg} / \mathrm{mg} / \mathrm{d}$ (table 1 ).

Similarly, the relative consumption rates (RCR) of insects were significantly reduced in a dose-dependent manner. The RCR of the insects were $0.161,0.079$ and $0.067 \mathrm{mg} / \mathrm{mg} / \mathrm{d}$ for $1.25,2.5$ and $5 \%$ concentrations of petroleum ether extract of $V$. negundo respectively. In the case of the control, the RCR was $0.23 \mathrm{mg} / \mathrm{mg} / \mathrm{d}$ (table 1).

On the other hand, the percentage of efficiency of conversion of ingested food (ECI \%) of the insects increased with an increase in the concentration of VPE. Higher ECI \% was shown by $2.5 \%$ (ECI = $43 \%)$ and $5 \%(E C I=41 \%)$ concentrations of the extract. Values of ECI calculated for a concentration of $1.25 \%$ of VPE was almost equal to the value (25\%) obtained for the control (23\%) (table 1).

\section{Feeding deterrence index for VPE}

Significant feeding deterrent activity or antifeedant activity against $T$. castaneum adults was exhibited by VPE at different concentrations in a dose-dependent manner. The feeding deterrence indices (FDI \%) increased gradually from about $34 \%$ to $69 \%$ and $74 \%$ respectively with VPE of 1.25, 2.5 and $5 \%$ concentrations (table 1). 
Table 1: Nutritional and feeding deterrence indices for $T$. castaneum adults treated with $V$. negundo petroleum ether extract

\begin{tabular}{|c|c|c|c|c|}
\hline Concentrations of the extracts (\%) & RGR (mg/mg/d) & $\mathrm{RCR}(\mathrm{mg} / \mathrm{mg} / \mathrm{d})$ & ECI (\%) & FDI (\%) \\
\hline VPE Control & $0.052 \pm 0.004$ & $0.23 \pm 0.022$ & $23.19 \pm 2.07$ & -- \\
\hline VPE 1.25 & $0.040 \pm 0.004^{*}$ & $0.161 \pm 0.004^{* *}$ & $25.30 \pm 2.20^{* *}$ & $34.48^{* * *}$ \\
\hline VPE 2.50 & $0.033 \pm 0.003^{*}$ & $0.079 \pm 0.007^{* *}$ & $43.17 \pm 6.36^{* *}$ & $68.52 * * *$ \\
\hline VPE 5.00 & $0.028 \pm 0.008^{*}$ & $0.067 \pm 0.006^{* *}$ & $41.21 \pm 9.91 * *$ & $73.88 * * *$ \\
\hline
\end{tabular}

Values are expressed as means \pm SEMs $(n=6)$; Sample: 10 insects $\times 4$ treatments $\times 6$ replications = Total 240 insects; RGR (relative growth rate) $*$ Not significantly different from the control (ANCOVA, $P=0.37$ ); RCR (relative consumption rate) ${ }^{* *} P<0.05$ when compared to control (ANCOVA); ECI (efficiency of conversion of ingested food) ${ }^{* *} P<0.05$ when compared to control (ANOVA); FDI (feeding deterrence index) ${ }^{* * *} P<0.001$ when compared to control (ANOVA); VPE: V. negundo petroleum ether extract.

\section{Nutritional indices for $V$. negundo methanol extract (VME)}

The relative growth rates of the insects were inhibited by different concentrations of VME in a dose-dependent manner. A concentration of $1.25 \%$ of VME brought about only a small decrease in RGR from the control value (from 0.046 to $0.044 \mathrm{mg} / \mathrm{mg} / \mathrm{d}$ ). Higher concentration $(2.5 \%)$ was found to be very effective in reducing the RGR to $0.024 \mathrm{mg} / \mathrm{mg} / \mathrm{d}$.

The highest concentration of the extract (5\%) was also showing a similar effect. There was only a very slight increase in the RGR $(0.027 \mathrm{mg} / \mathrm{mg} / \mathrm{d})$ (table 2). Similarly, relative consumption rate (RCR) also significantly decreased with increasing concentrations of the extract. With a concentration of $1.25 \%$ of the extract the control value of $0.169 \mathrm{mg} / \mathrm{mg} / \mathrm{d}$ was reduced to $0.113 \mathrm{mg} / \mathrm{mg} / \mathrm{d}$, which was then reduced to 0.073 $\mathrm{mg} / \mathrm{mg} / \mathrm{d}$ with $2.5 \%$ of the VME.
However, the RCR showed only a slight decrease when the concentration was further increased to $5 \%$. The value was 0.063 $\mathrm{mg} / \mathrm{mg} / \mathrm{d}$ (table 2). In the case of the percentage of efficiency of conversion of ingested food (ECI \%) of the insects, there was an increase in the case of $1.25 \%$ of VME (39\%) from the control value of $28 \%$. This value was seen to drop to $31 \%$ when the concentration of the extract was increased to $2.5 \%$. However, this drop was overcome when the concentration was increased to $5 \%$. The ECI value was $48 \%$ in this case (table 2).

\section{Feeding deterrence index for VME}

Like VPE, VME also exhibited significant feeding deterrent activity against $T$. castaneum. It was seen that here also, the feeding deterrence index (FDI \%) increased in a dose-dependent manner. The FDI \% were 37, 58 and $66 \%$, respectively, for $1.25,2.5$ and $5 \%$ of the extract (table 2).

Table 2: Nutritional and feeding deterrence indices for $T$. castaneum adults treated with V. negundo methanol extract

\begin{tabular}{llll}
\hline Concentrations of the extracts (\%) & RGR (mg/mg/d) & RCR (mg/mg/d) & ECI (\%) \\
\hline VME Control & $0.046 \pm 0.004$ & $0.169 \pm 0.023$ & $27.77 \pm 1.02$ \\
VME 1.25 & $0.044 \pm 0.007^{*}$ & $0.113 \pm 0.007^{* *}$ & $38.89 \pm 5.20^{* *}$ \\
VME 2.50 & $0.024 \pm 0.006^{*}$ & $0.073 \pm 0.007^{* *}$ & $31.13 \pm 5.27^{* *}$ \\
VME 5.00 & $0.027 \pm 0.005^{*}$ & $0.063 \pm 0.008^{* *}$ & $36.75^{* * *}$ \\
\hline
\end{tabular}

Values are expressed as means \pm SEMs $(\mathrm{n}=6)$; Sample: 10 insects $\mathrm{x} 4$ treatments $\mathrm{x} 6$ replications $=$ Total 240 insects; RGR (relative growth rate) $*$ Not significantly different from the control (ANCOVA, $P=0.37$ ); RCR (relative consumption rate) ${ }^{* *} P<0.05$ when compared to control (ANCOVA); ECI (efficiency of conversion of ingested food) ${ }^{* *} P<0.05$ when compared to control (ANOVA); FDI (feeding deterrence index) ${ }^{* * *} P<0.001$ when compared to control (ANOVA); VME: V. negundo methanol extract.

\section{Comparison of the effects of VPE and VME on T. castaneum}

The effects of VPE and VME on RCR of T. castaneum were compared (fig. 1). The data showed that the effects on RCR of the insects were similar with both the extracts (ANCOVA, $P=0.80$ ). However, there were showing a dose-dependent decrease of RCR (ANCOVA, $P<0.05$ ) of the insects with both the extracts. Analysis of ECI (\%) for VPE and VME showed (fig. 2) similar activity (ANOVA, $P=0.75$ ) and the extracts showed an increase in the ECI (\%) of the insects with an increase in the concentrations (ANOVA, $P<0.05$ ).

The data of FDI (\%) showed (fig. 3) similar activities (ANOVA, $P=0.07)$ of the two extracts. On the other hand, there was a dosedependent increase (ANOVA, $P<0.001$ ) of FDI $(\%)$ of the insects with each extract. Comparison of RGR of the insects was showed similar activity (ANCOVA, $P=0.49$ ) with both the extracts.

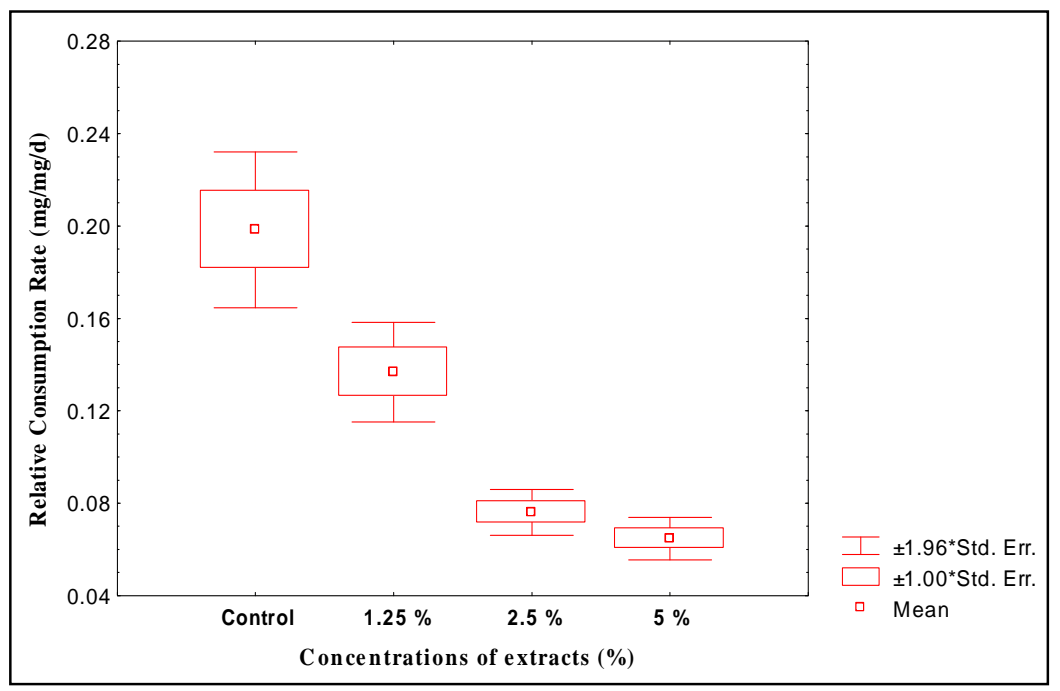

Fig. 1: Categorised plot for variable of RCR for T. castaneum for different concentrations of VPE and VME 
The data represent the pooled values for the effects of VPE and VME for different concentrations used. The difference between the activities of the two extracts was not significant (ANCOVA, $P=$ $0.80)$.

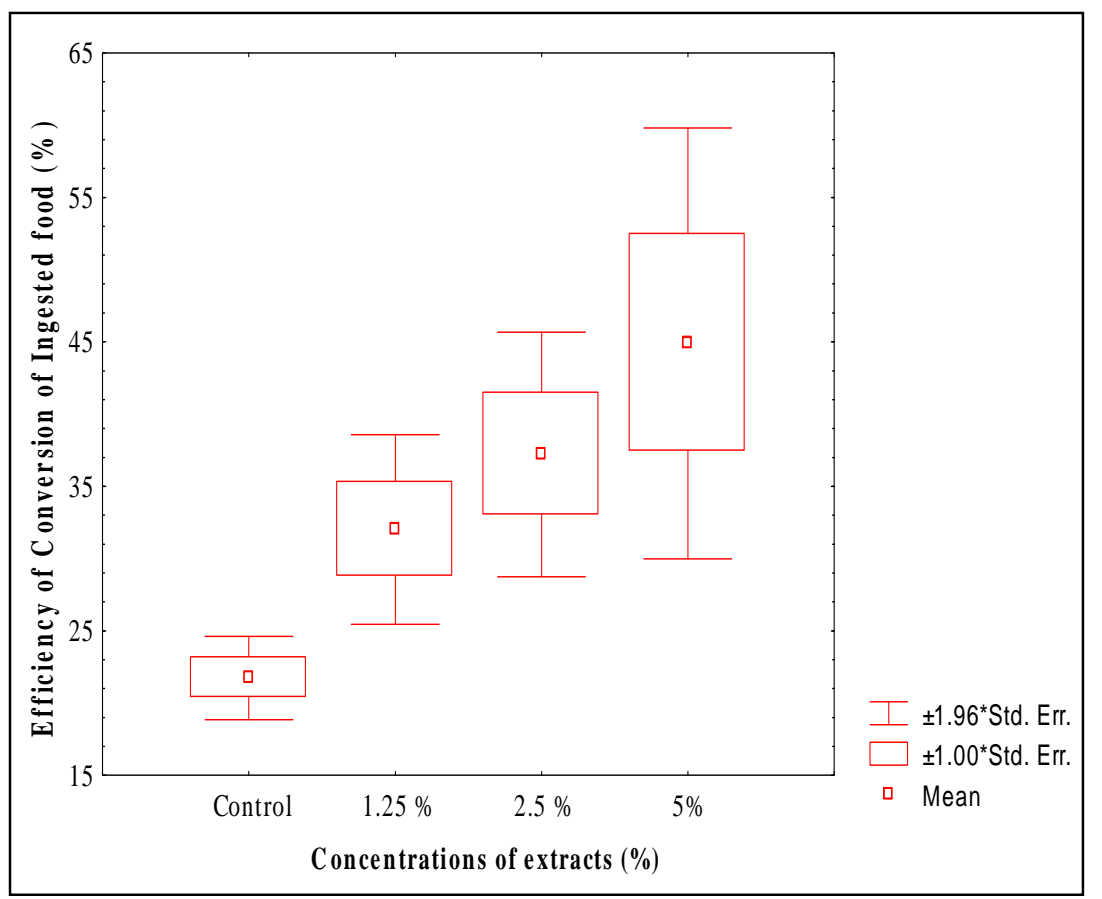

Fig. 2: Categorised plot for variable of ECI \% for T. castaneum for different concentrations of VPE and VME

The data represent the pooled values for the effects of VPE and VME for different concentrations used. The difference between the activities of VPE and VME was not significant (ANOVA, $P=$ $0.75)$.

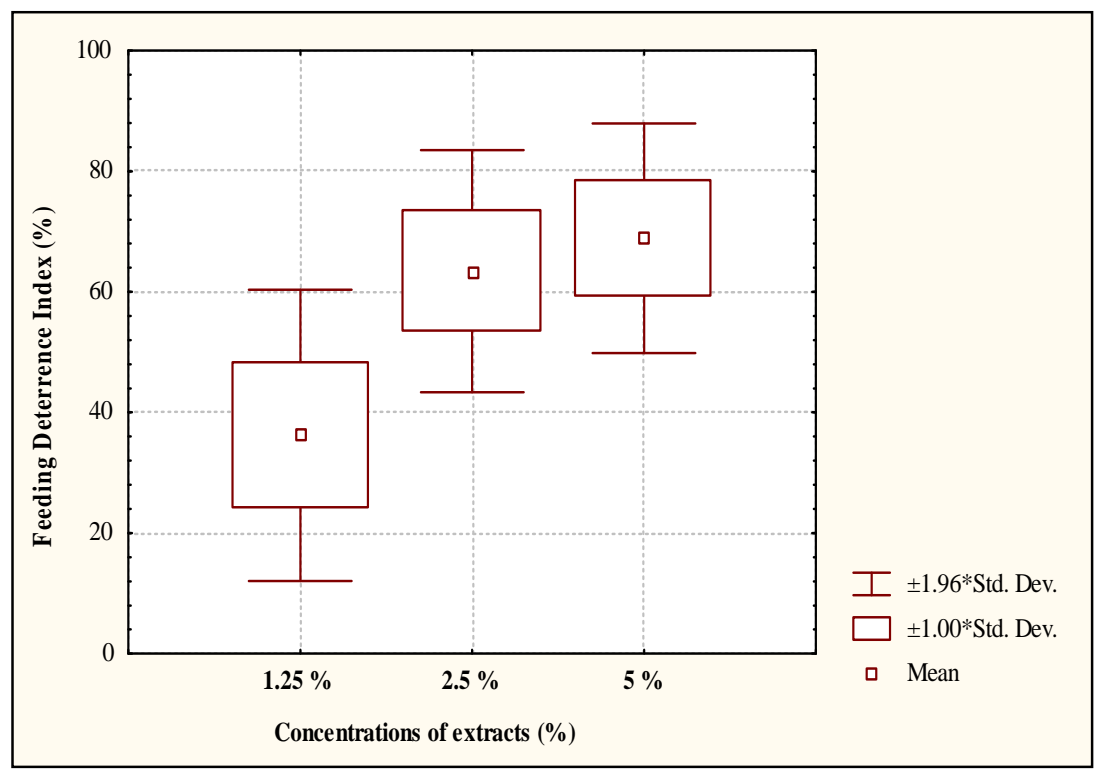

Fig. 3: Categorized plot for variable of FDI \% for T. castaneum for different concentrations of VPE and VME

The data represent the pooled values for the effects of VPE and VME for different concentrations used. The difference between the activities of VPE and VME was not significant (ANOVA, $P=0.07$ ).

\section{DISCUSSION}

The reduction of RGR and RCR of T. castaneum by both the extracts observed in this study are in agreement with similar studies of various other workers. Reduction of growth and food consumption of $T$. castaneum and $S$. zeamais was brought about by essential oils of nutmeg seeds [14] and by cinnamaldehyde from C. aromaticum [15]. Allyl disulphide, a volatile compound from garlic, Allium sativum 
[16], and 1,8-cineole from A. апnua [17] were found to cause significant reduction of RGR and RCR of $T$. castaneum. The reduction of growth and food consumption of T. castaneum observed in this study (fig. 1) may presumably be due to the antifeedant action of the extract incorporated into the diets. This study also reveals that the quantity of food material converted to body matter is reduced and that the consumption of a lesser quantity of the treated food is likely to be the main cause of growth inhibition.

In the nutritional studies, it was also seen that with both the extracts, increase in the concentration resulted in an increase in the efficiency of conversion of ingested food (ECI \%) significantly $(P<0.05)$. It was seen that the difference between the activities of these two extracts on ECI was not significant $(P=0.75)$ (fig. 2). Significantly higher ECI values over the control were obtained with all concentrations of the extracts in the present study. Moreover, there appeared to be a dose-dependency for this effect. Similar observations were reported in Crocidolomia binotalis [18] and Spodoptera litura [19]. Similarly, Joseph reported [20] higher ECI \% from his studies of antifeedancy and growth inhibitory effects of neem seed kernel extract on Ailanthus defoliator, Eligma narcissus indica. Present study using $V$. negundo against $T$. castaneum show higher ECI values which presumably reflect the compensation for antifeedant effect as suggested by Fagoonee who reported [18] the neem related high ECI and ECD values in Crocidolomia binotalis.

It was also found that the extracts exerted significant feeding deterrence (antifeedancy) on this insect (fig. 3). The feeding deterrence was found to be dose-dependent and increased by all the concentrations of the two extracts were found to be significant $(P<0.001)$. However, the activity was similar with both the extracts $(P=0.07)$. Antifeedant effects of $V$. negundo have been reported earlier. Premeela and Muraleedharan reported [21] that certain phytochemicals in the extracts of $V$. negundo caused a significant reduction in the levels of all the three digestive enzymes (midgut protease, invertase and amylase) and thus inhibited food digestion in the red cotton bug. Dysdercus cingulatus. Extracts of $V$. negundo, [18] and essential oils derived from this plant [22] have been reported to exhibit antifeedant activities against Spodoptera litura.

Several essential oil constituents contained in the petroleum ether and methanol extracts of $V$. negundo leaves may be responsible for the antifeedant activity against T. castaneum. GC and GC-MS analysis of the essential oils of $V$. negundo leaves [23] revealed that this oil contain 65 known compounds, including sabinene p-cymene, betaphellandrene, gamma-terpinene, terpinene-4-ol, beta-caryophyllene, alpha-guaiene, spathulenol, beta-caryophyllene oxide, globulol, viridiflorol, bis [1,1-dimethyl]-methylphenol, abieta-7, 13-diene and several minor unidentified compounds. Jirovetz et al. investigated [24] the essential oil components of the leaves of $V$. negundo var. negundo and V. negundo var. purpurescens by GC-FID, GC-MS and olfactometry. They isolated monoterpenes (terpinen-4-ol, p-cymene, a-terpineol, sabinene) and sesquiterpenes (b-caryophyllene, globulol, spathulenol, b-farnesene and bis [1,1-dimethyl] methyl phenol) from the leaves of the two varieties of $V$. negundo. Hebbalkar et al. reported [25] that oils from $V$. negundo leaves when analysed by column chromatography and IDCC technique revealed that it contained several components such as $\alpha$-terpenine, $\gamma$-terpenine, $p$ cymene, a mixture of sesquiterpene hydrocarbons, 4-terpineol, monoterpenes, sesquiterpenes and a mixture of monoterpene and sesquiterpene alcohols. The majority of components present in the fractions exhibited repellent activity against A. aegypti. These essential oil constituents present in the leaf extracts presumably are responsible for antifeedant activity against $T$. castaneum. Several volatile constituents of $V$. negundo leaves were analysed by GC-MS [26]. The main components detected were viridiflorol, bcaryophyllene, sabinene, 4-terpineol, g-terpinene, caryophyllene oxide, 1-oceton-3-ol and globulol. These components in the leaves may also act as antifeedants against $T$. castaneum.

The mechanism of perception of inhibitory chemicals in insects has been reviewed by Chapman [27] and Schoonhoven [28]. On the basis of behavioural and electrophysiological studies, parts of the body on which the relevant receptors are located and the mechanism by which insects differentiate inhibitory and stimulatory materials have been established [27]. Antennae in insects are generally considered to be the main organ for the perception of smell in insects [29] and they would be expected to be involved in responses to olfactory repellents. The experiments of Haskell and Mordue [30] suggested that sensilla on the tip of the labrum have a primary role in the detection of inhibitory chemicals in S. gregaria. These mechanisms of perception of inhibitory chemicals in feeding may also occur in $T$. castaneum adults in response to $V$. negundo leaf extractincorporated wheat flour diets. Various chemical components extracted from $V$. negundo in petroleum ether and methanol presumably inhibit the feeding of the insect and perception of these chemicals is effected by the receptors like sensilla on the antennae, labrum, maxillary and labial palps of $T$. castaneum.

Electrophysiological studies have indicated that inhibitory phytochemicals may be involved in the antifeedancy in insects. These chemicals may either directly inhibit the input from the phagostimulant receptor, or the signals may be interpreted as inhibitory at the central nervous system [31, 32 and 33]. Similar electrophysiological mechanism of perception of inhibitory chemicals may also be active in $T$. castaneum with regard to the response to the extract incorporated diets. Active phytochemicals in the extracts presumably suppress the activity of the receptor cells of these insects or input signal from the receptor neuron can be perceived by the central nervous system in which it is interpreted as inhibitory and may cause an antifeedant effect.

\section{CONCLUSION}

The present study thus reveals that both petroleum ether and methanol extracts of $V$. negundo show significant reduction of consumption and utilisation of food and thereby bring about antifeedancy to $T$. castaneum. Since antifeedant action offers a valuable weapon against this pest, further study on the effect of these extracts on other stored products insects and phytophagous insects should be carried out. This also suggested that there may be different chemical constituents in both the extracts responsible for antifeedancy in a dose-dependent manner. So, further analytical studies should be carried out to determine the exact chemical structure of the bioactive components in the extracts of $V$. negundo to understand how each of the constituent influences the physiology and behaviour of the insects. Moreover, it might be worthwhile if the insect antifeedant components of $V$. negundo are produced commercially so that their potential in controlling stored product pests can be fully exploited.

\section{ACKNOWLEDGEMENT}

P. Haridasan is grateful to the University Grants Commission (UGC), New Delhi, for the award of a teacher fellowship under FIP.

\section{CONFLICT OF INTERESTS}

\section{Declared none}

\section{REFERENCES}

1. Talukder FA, Howse PE. Deterrent and insecticidal effects of extracts of pithraj, Aphanamixis polystachya (Meliaceae), against Tribolium castaneum in storage. J Chem Ecol 1993;19:2463-71.

2. Talukder FA, Howse PE. Isolation of secondary plant compounds from Aphanamixis polystachya as feeding deterrents against adult Tribolium castaneum (Coleoptera: Tenebrionidae). J Plant Diseases Protect 2000;107:498-504.

3. Chandel BS, Chauhan RRS, Kumar A. Phagodeterrent efficacy of rhizome extract of sweetflag, Acorus calamus against Tribolium castaneum. Indian J Entomol 2001;63:8-10.

4. Liu JK, Jia ZJ, Wu DG, Zhou J, Wang QC. Insect antifeeding agents: sesquiterpene alkaloids from Celastrus angulatus. Phytochem 1990;29:2503-6.

5. Archana T, Kumar ML, Saxena RC, Tiwari A, Lakshamana KM. Effect of Nicotiana tabacum on Tribolium castaneum. Int J Pharmacogn 1995;33:348-50.

6. Lad H, Dixit D, Joshi A, Bhatnagar D. Antioxidant and antiinflammatory effects of Vitex negundo on FREUND'S complete adjuvant induced arthritis. Int J Pharm Pharm Sci 2015;7:81-5. 
7. Vangoori Y, Klnrr D, Gadekal M, Ramesh P. Evaluation of antiulcer activity of ethanolic extract of leaves of Vitex negundo on pylorus ligature-induced and aspirin ligature-induced ulcerin albino rats. Int J Pharm Pharm Sci 2013;5:476-8.

8. Karthikeyan V, Sivakumar K, Gokuldass A, Mohanasundaran S. Studies on the larvicidal activity of Leucas aspera, Vitex negundo and Eucalyptus against Culex quinquefasciatus collected from Coovum river of Chennai, India. Asian J Pharm Clin Res 2009;2:81-6.

9. Patel J, Shah S, Deshpande S, Shah G. Evaluation of the antiasthmatic activity of leaves of Vitex negundo. Asian J Pharm Clin Res 2012;5 Suppl 3:189-92.

10. Xie YS, Bodnary RP, Fields PG. A rapid and simple flour disc bioassay for testing natural substances active against storedproduct insects. Cana Entom 1996;128:865-75.

11. Manuwoto S, Scriber JM. Consumption and utilization of three maize genotypes by southern armyworm. J Econ Entomol 1982;75:163-7.

12. Farrar RR, Barbour JD, Kennedy GG. Quantifying food consumption and growth in insects. Ann Entomol Soc Am 1989;82:593-8.

13. Isman MB, Koul O, Luczynski A, Kaminiski J. Insecticidal and antifeedant bioactivities of neem oil and their relationship to azadiractin content. J Agric Food Chem 1990;38:1406-11.

14. Huang Y, Tan JMWL, Kini RM, Ho SH. The toxic and antifeedant action of nutmeg oil against Tribolium castaneum (Herbst.) and Sitophilus zeamais Motsch. I Stored Prod Res 1997;33:289-98.

15. Huang Y, Ho SH. Toxicity and antifeedant activities of cinnamaldehyde against the grain storage insects, Tribolium castaneum (Herbst) and Sitophilus zeamais. J Stored Prod Res 1998;34:11-7.

16. Chiam WY, Huang Y, Chen SX, Ho SH. Toxic and antifeedant effects of allyl disulfide on Tribolium castaneum (Coleoptera: Tenebrionidae) and Sitophilus zeamais (Coleoptera: Curculionidae). J Econ Entomol 1999;92:239-45.

17. Tripathi AK, Prajapati V, Aggarwal KK, Kumar S. Toxicity, feeding deterrence, and effect of the activity of 1, 8-cineole from Artemisia annua on progeny production of Tribolium castaneum (Coleoptera: Tenebrionidae). J Econ Entomol 2001;94:979-81.

18. Fagoonee I. Effect of azadirachtin and of a neem extract on food utilization by Crocidolomia bionotalis. Proc. $2^{\text {nd }}$. Int Neem Conf Rauischholzhansen; 1983. p. 221-4.

19. Sahayaraj K. Antifeedant effect of some plant extracts in the Asian armyworm, Spodoptera litura (Fabricius). Curr Sci 1998;74:523-5.
20. Joseph TM. Antifeedant and growth inhibitory effects of neem seed kernel extract on Ailanthus defoliator, Eligma narcissus indica Roth. (Lepidoptera: Noctuidae). Entomon 2000;25:67-72.

21. Premeela M, Muraleedharan D. Inhibition of food digestion by certain phytochemicals in the red cotton bug, Dysdercus cingulatus. Fabr. (Heteroptera: Pyrrhocoridae). Proc Indian Nat Sci Acad Part B Biol Sci 1995;61:389-94.

22. Sharma SS, Gill K, Malik MS, Malik OP. Insecticidal, antifeedant and growth inhibitory activities of essential oils of some medicinal plants. J Med Arom Plant Sci 2000;22/23:373-7.

23. Mallavarapu GR, Srinivasaiyer R, Kaul PN, Battacharya AK, Rao BRR, Ramesh S. Chemical composition of the essential oil of the leaves of Vitex negundo. Planta Med 1994;60:583-4.

24. Jirovetz L, Buchbauer G, Puschmann C, Shafi MP, Nambiar MKG: Analysis of the essential oils of the leaves of the medicinal plants Vitex negundo var. negundo and Vitex negundo var. purpurescens from India. Acta Pharm 1998;48:179-86.

25. Hebbalkar DS, Hebbalkar GD, Sharma RN, Joshi VS, Bhat VS Mosquito repellent activity of oils from Vitex negundo Linn. leaves. Indian J Med Res 1992;95A:200-3.

26. Singh V, Dayal R, Bartley JP. Volatile constituents of Vitex negundo leaves. Planta Med 1999;65:580-2.

27. Chapman RF. The chemical inhibition of feeding by phytophagous insects: a review. Bull Ent Res 1974;64:339-63.

28. Schoonhoven LM. Biological aspects of antifeedants. Ent Exp Appl 1982;31:57-69.

29. Dethier VG. The Physiology of Insect Senses. London, Methuen; 1963. p. 266.

30. Haskell PT, Mordue (Luntz) JA. The role of mouth part receptors in the feeding behaviour of Schistocerca gregaria and Locusta migratoria migratorioides. Ent Exp Appl 1969;12:777-8.

31. Ma WC. Dynamics of feeding responses Pieris brassicae Linn. as a function of chemosensory input: a behavioural, ultrastructural and electrophysiological study. Meded Landb Hoogesch, Wageningen 1972;72:162.

32. Ishikawa S, Hirao T, Arai N. Chemosensory basis of host plant selection in the silkworm. Ent Exp Appl 1969;12:544-54.

33. Ma WC. Some properties of gustation in the larva of Pieris brassicae. Ent Exp Appl 1969;12:584-90.

\section{How to cite this article}

- $\quad$ P Haridasan, M. Gokuldas, A. P. Ajaykumar. Antifeedant effects of Vitex negundo L. leaf extracts on the stored product pest, Tribolium castaneum H. (coleoptera: tenebrionidae). Int J Pharm Pharm Sci 2017;9(3):17-22. 